\title{
Reestruturação intraurbana de cidades médias
}

Intra-urban restructuring of medium-sized cities

\section{Diego Ferretto*}

*Arquiteto urbanista pela Universidade Federal de Santa Catarina - (UFSC), 2007, Doutor em Planejamento Urbano e Regional pela Faculdade de Arquitetura e Urbanismo da Universidade de São Paulo (FAUUSP), 2018. Professor dos cursos de Graduação em Arquitetura e Urbanismo da Universidade Paulista (UNIP) e do Centro Universitário FIAM-FAAM da rede Laureate International Universities e a Laureate Education.

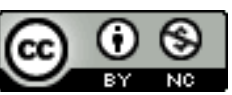

Recebido: 05/05/2020

Aceito: $16 / 06 / 2020$

https://doi.org/10.37916/arq.urb.v28i.434

usjt • arq.urb • número 28 | maio - agosto de 2020

\section{Abstract}

Este artigo tem por objetivo analisar a disseminação de shopping centers e condomínios fechados de alta renda em cidades médias, a partir dos casos das cidades de Caxias do Sul, Passo Fundo, Pelotas e Santa Maria, localizadas no estado do Rio Grande do Sul. A emergência desses espaços, por um lado, associa-se a estratégias capitalistas de reprodução do capital, vinculadas a grandes grupos empresariais e sobretudo ao setor imobiliário, que têm na cidade média um mercado consumidor em potencial; por outro lado, indica processos de reestruturação intraurbana em curso. Os shopping centers denotam novas expressões da centralidade, para além dos centros principais, enquanto os condomínios fechados implantados em áreas periféricas representam a dispersão das classes de alta renda, tradicionalmente localizadas nas áreas centrais, promovendo a ampliação da fragmentação socioespacial. Esses fatos, juntos, permitem a utilização do conceito de reestruturação, pressupondo rupturas significativas nas lógicas de estruturação intraurbanas precedentes.

Palavras-chave: estrutura intraurbana, shopping center, condomínio fechado.
This article aims to analyze the dissemination of high-income shopping centers and gated communities in medium-sized cities, based on the cases of the cities of Caxias do Sul, Passo Fundo, Pelotas and Santa Maria, located in the state of Rio Grande do Sul. the emergence of these spaces, on the one hand, is associated with capitalist strategies for the reproduction of capital, linked to large business groups and above all to the real estate sector, which have a potential consumer market in the average city; on the other hand, it indicates ongoing intra-urban restructuring processes. Shopping centers denote new expressions of centrality, in addition to the main centers, while closed condominiums located in peripheral areas represent the dispersion of high-income classes, traditionally located in central areas, promoting the expansion of sociospatial fragmentation. These facts, together, allow the use of the concept of restructuring, assuming significant breaks in the previous intraurban structuring logic.

Keywords: intra-urban structure, shopping center, gated community. 


\begin{abstract}
1. Com destaque à produção vinculada à ReCiMe (Rede de Pesquisadores sobre as Cidades Médias), fundada em 2007, sobretudo a partir das obras: Cidades médias: produção do espaço urbano e regional (2006), Cidades médias: espaços em transição (2007) e à série de publicações denominada "Cidades em Transição", que contempla a divulgação de resultados de pesquisa da rede, apresentando os casos das cidades de Passo Fundo e Mossoró (2010), Tandil e Uberlândia (2010), Chillán e Marília (2012), Campina Grande e Londrina (2013), Marabá e Los Ángeles (2015) e Dourados e Chapecó (2016).

2. O artigo atualiza e a aprofunda as reflexões efetuadas em FERRETTO (2018).
\end{abstract}

usjt • arq.urb • número 28 | maio - agosto de 2020

\section{Introdução}

interesse pelas cidades médias como recorte analítico se justifica diante de sua crescente importância na rede urbana brasileira, a partir da ampliação de funções, mas também diante da complexificação de suas estruturas intraurbanas. A definição de cidade média extrapola critérios demográficos e reconhece nesses espaços a realização de funções de intermediação no âmbito de uma rede urbana considerando-se relações que se estabelecem em diferentes escalas, da regional à global (SPOSITO et al., 2006). Há significativa literatura sobre o tema, revelando esforços teóricos em torno da definição de cidade média, assim como recortes empíricos voltados à compreensão de suas especificidades, abarcando diferentes escalas de abordagem ${ }^{1}$.

O texto privilegia a escala intraurbana de análise, tendo por objetivo discutir os processos de reestruturação em curso nas cidades de Caxias do Sul, Passo Fundo, Pelotas e Santa Maria ${ }^{2}$, a partir da análise da implantação de shopping centers e condomínios fechados de alta renda. As cidades em destaque correspondem às principais cidades médias do Rio Grande do Sul, tendo em comum as funções de polos regionais exercidas através da oferta de comércio e de serviços especializados às suas respectivas áreas de influência.
Segundo Sposito e Góes (2013, p.278), a adoção do termo "reestruturação" indica momentos de ruptura com as lógicas precedentes que orientam a produção do espaço urbano. Parte-se da hipótese que, nas cidades médias, a emergência de condomínios fechados de alta renda e de shopping centers, nesse início de século, representam rupturas significativas nos processos de estruturação intraurbana precedentes. Os condomínios denotam novos padrões espaciais de (auto)segregação das classes de alta renda em áreas periféricas, enquanto os shopping centers representam novas expressões da centralidade associadas a grandes equipamentos privados. Juntos, esses dois elementos promovem alterações na estrutura intraurbana, influenciando novos arranjos e dinâmicas que denotam a ampliação dos processos de fragmentação socioespacial.

Corrêa (2010, p.150) associa os condomínios fechados e shopping centers a inovações espaciais que propiciam a formação de "setores seletivos, dotados de amenidades e apropriados pela classe média alta e pela elite". Segundo o autor, as inovações se constituem como os meios pelos quais o capitalismo garante sua existência e reprodução, envolvendo estratégias de destruição e obsolescência programada; a ideia do novo, presente nos bens 
de consumo de massa, sinônimo de progresso e bem-estar, forjada pela publicidade, torna-se objeto de consumo.

Caldeira (2011, p.258) enquadra os condomínios fechados e shopping centers em uma categoria mais ampla denominada "encaves fortificados", juntamente aos conjuntos de escritórios e outros espaços adaptados como centros de lazer, parques temáticos, escolas e hospitais. Os enclaves fortificados têm em comum a propriedade privada de uso coletivo, a valorização do espaço privado, o isolamento por muros e, essencialmente, a negação da dimensão do espaço público, promovendo uma ruptura com a cidade. Caldeira observa que a construção de símbolos de status vinculados aos enclaves fortificados exigiu mudanças de valores das classes médias e de alta renda, a partir da aceitação de residências coletivas, em regime de condomínio, frente às residenciais individuais, e da valorização de áreas periféricas, não urbanizadas frente às áreas centrais e seus bairros tradicionais.

Essa mudança requereu a inversão dos valores que haviam prevalecido dos anos 40 até os 80 quando o centro era inequivocamente associado aos ricos e a periferia, aos pobres. Prela primeira vez, algo como o subúrbio americano tornou-se popular entre a elite, e a distância do centro foi ressignificada pra conferir status em vez de estigma (CALDEIRA, 2011, p.259-60).
Frúgoli Jr. (1992), a partir uma leitura antropológica, destaca que os shoppings centers se colocam como um contraponto às deficiências das cidades, buscando reproduzir em espaços controlados cidades em miniatura, dialogando inclusive com signos urbanos como a praça, o boulevard e o comércio. $\mathrm{O}$ autor defende que esses equipamentos aspiram, portanto, "traduzir, num espaço fechado, a utopia urbana que o capitalismo moderno não realizou para o conjunto da sociedade: uma 'cidade ideal', repleta apenas de cidadãos consumidores, sem vestígios de pobreza e deterioração" (FRÚGOLI JR.,1992, p.77).

A partir dos objetivos e pressupostos teóricos elencados, o artigo está estruturado em três partes: as duas primeiras visam caracterizar, quantitativa, qualitativa e temporalmente a disseminação de shopping centers e condomínios fechados de alta renda nas cidades estudadas; na última parte tem-se por objetivo analisar a inserção espacial desses elementos, visando compreender a maneira como se relacionam entre si e com a estrutura intraurbana, apontando as dinâmicas que permitem-nos identificar processos de reestruturação em curso.

\section{Shopping centers}

Os shopping centers surgem nos Estados Unidos, no contexto de crescimento econômico e metropolização do pós-guerra, nas décadas de 1940 e 1950. No Brasil, começam a aparecer a partir da década 


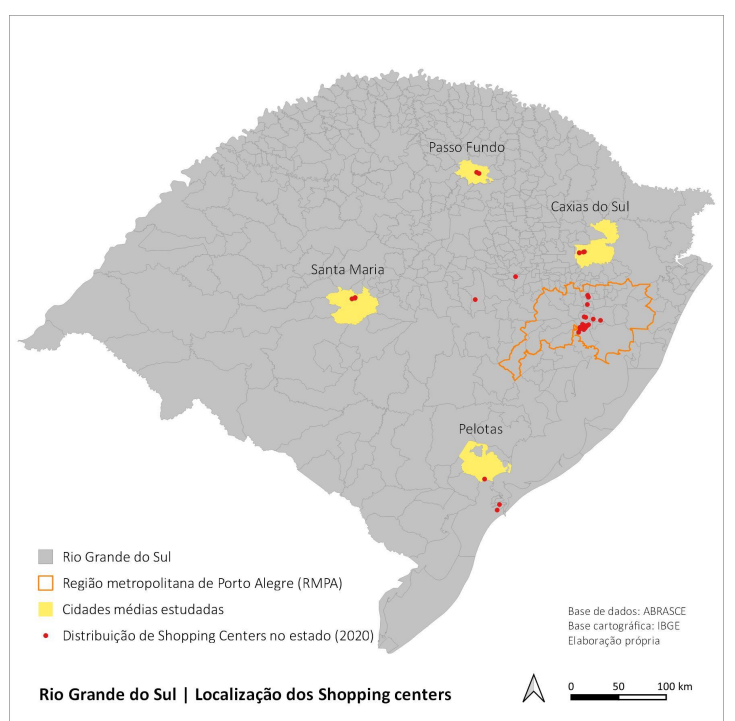

Figure 1

Fonte: elaboração própria

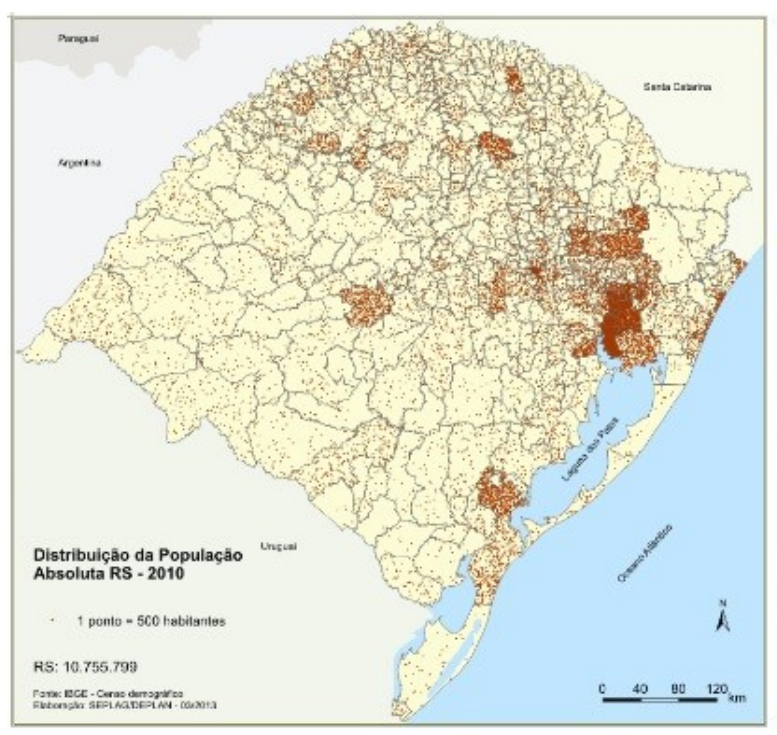

Figura 2

Fonte: Atlas Socioeconômico do Rio Grande do Sul

usjt • arq.urb • número 28 | maio - agosto de 2020 de 1960, sendo a cidade de São Paulo precursora (shopping Iguatemi, 1966), no entanto, é a partir da década de 1980 que se multiplicam, preferencialmente nas capitais, mas também em algumas cidades médias, inicialmente no estado de São Paulo, a exemplo de Campinas (1980), Ribeirão Preto (1981), Presidente Prudente (1986) e São José dos Campos (1987) (PINTAUDI, 1992).

A Associação Brasileira de Shopping Centers (ABRASCE) considera shopping centers empreendimentos com pelo menos $5.000 \mathrm{~m}^{2}$ de Área Bruta Locável (ABL). Segundo dados da ABRASCE, em 2019, havia 577 shoppings no país, a maioria, $52 \%$, na região sudeste; a região sul abrigava $17 \%$ do total. Dados de 2017 indicam que 46\% dos

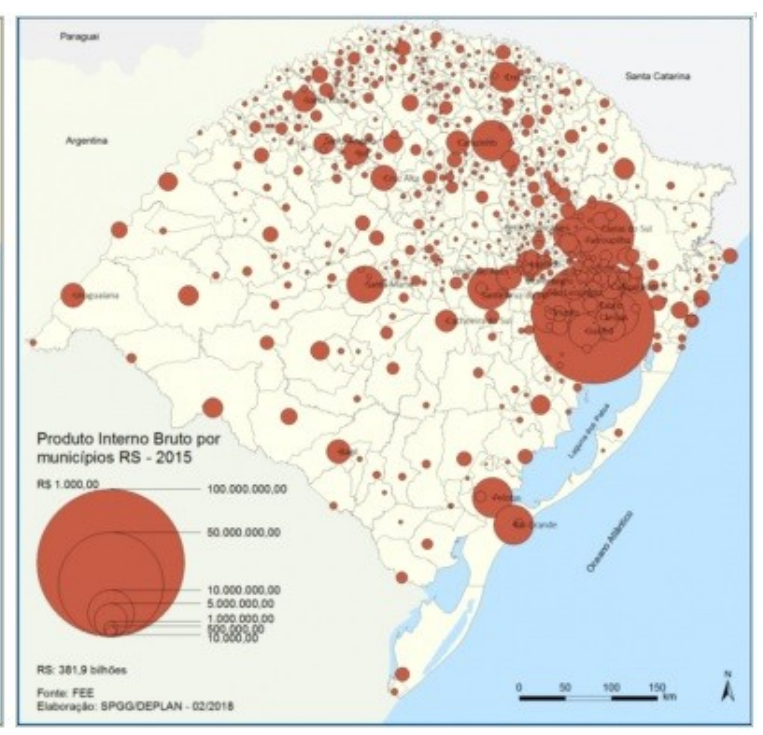

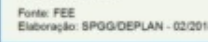

shoppings estavam nas capitais, do percentual restante, $43 \%$ localizados em cidades com menos de 500 mil habitantes; no mesmo ano, $75 \%$ das inaugurações ocorreram fora das capitais, o que evidencia sua desconcentração e o interesse pelas cidades médias.

Atualmente, o Rio Grande do Sul é o quarto estado brasileiro que concentra o maior número de shopping centers, atrás de São Paulo, Rio de Janeiro e Minas Gerais, dos 37 shoppings em operação no estado, 23 estão na região metropolitana de Porto Alegre, sendo 16 na capital, e o restante em sete cidades do interior do estado, Caxias do Sul, Lajeado, Passo Fundo, Pelotas, Rio Grande, Santa

Cruz do Sul e Santa Maria.

Geograficamente, conforme demonstra o mapa (figura 1), evidencia-se a concentração de shoppings especialmente na região metropolitana de Porto Alegre (RMPA), além da presença desses equipamentos nas cidade polo-regionais: Passo Fundo, na região norte, Caxias do Sul, na serra gaúcha, Santa Maria e Santa Cruz do Sul, no centro de estado, e Pelotas e Rio Grande, na região Sul. Essas regiões correspondem às áreas mais populosas e de maior dinamismo econômico do estado, conforme expressam nos mapas da figura 2.

O primeiro shopping do estado é de 1970, inaugurado Porto Alegre, o segundo, também na capital, é 
de 1983, no entanto, é na década de 1990 que esses equipamentos se multiplicam, com a adição de 14 unidades, oito na RMPA e seis no interior, sendo três em Caxias do Sul, um em Santa Maria, um em Lajeado e um em Passo Fundo. Na década de 2000, são mais 10 empreendimentos, somente dois fora da RMPA, nas cidades de Santa Maria e Santa Cruz do Sul, no centro do estado. A última década registra ritmos crescentes, com a inauguração de mais 11 shoppings, revelando uma maior desconcentração em relação à década de 2000 , com quase metade dos empreendimentos no interior, distribuídos pelas cidades de Caxias do Sul, Pelotas, Passo Fundo, Rio Grande e Santa Maria.

Nesse contexto, dentre as cidades estudadas Caxias do Sul é a que apresenta maior dinamismo no setor, totalizando quatro shopping centers, três deles implantados na década de 1990 (Prataviera, Iguatemi e Martcenter) e um no ano de 2010 (Bourbon San Pelegrino); Santa Maria conta com três shoppings, o primeiro inaugurado no final da década de 1990 (Monet Plaza Shopping), o segundo em 2009 (Royal Plaza Shopping) e o terceiro em 2017 (Praça Nova Santa Maria); em Passo Fundo há dois shoppings, o primeiro de 1998 (Bella Cittá) e um mais recente, de 2018 (Shopping Passo Fundo); por fim, Pelotas conta somente com um shopping, o Shopping Pelotas, inaugurado em 2013.

\section{Condomínios fechados}

Os condomínios fechados horizontais constituem objeto recorrente de estudo no campo das ciências sociais, dada sua generalização a partir da década de 1990, em diversos países, sobretudo da América Latina. Predominantemente associados aos processos de dispersão urbana e à manifestação eloquente da autossegregação dos ricos nas cidades brasileiras, esses espaços disseminaram-se entre as classes médias e atualmente abarcam inclusive o mercado popular de habitação.

Nesse texto, a expressão "condomínios fechados" engloba áreas residenciais multifamiliares de acesso restrito (muradas ou cercadas), definidas por um conjunto de lotes que compartilham áreas comuns (vias, áreas livres, equipamentos) e tem acesso controlado. Essa denominação não se vincula aos estatutos jurídicos específicos dos empreendimentos estudados, semelhante a opção de Sposito e Góes (2013) ao utilizarem a expressão "espaços residenciais fechados" com o objetivo de abarcar as diferenças jurídicas entre os espaços estabelecidos em regime de propriedade condominial e os não condominiais loteados aos quais foi concedido o direito de cercamento, ou ainda aqueles que o fizeram sem qualquer autorização legal.

Freitas (2008, p.95) prefere o termo "loteamentos fechados" argumentando que os espaços residenciais fechados "são loteamentos convencionais apro- 
vados sob a Lei Federal 6.766/1979, que, com ou sem anuência das prefeituras, são cercados e murados". A autora argumenta que os loteamentos fechados, geralmente localizados nas franjas urbanas ou em áreas rurais, embora conhecidos também como condomínios possuem características distintas dos condomínios horizontais de casas (Lei Federal 4.591/1964), pois nos loteamentos fechados há somente implantação de infraestrutura e demarcação de lotes, enquanto nos condomínios é necessário a construção da edificação residencial. Nesse sentido, os loteamentos fechados são ilegais, pois privatizam áreas públicas, obstruindo o acesso às vias públicas e áreas livres, no entanto, diversas prefeituras utilizam artifícios para legitimar esses empreendimentos, embora aprovados como loteamentos abertos convencionais, segundo os critérios da Lei 6.766, seu fechamento posterior acaba sendo permitido pelo poder público, eventualmente amparado no artigo $7^{\circ}$ do Decreto-lei 271/67, que prevê concessão real de uso de áreas públicas.

Loyolla (2018) observa que diversos municípios buscaram legitimar o fechamento de loteamentos, criando regramentos específicos e contrariando a Lei Federal 6.766/1979. No âmbito federal, nas últimas duas décadas, houve a tramitação de alguns projetos de lei em torno dessa questão culminando na aprovação da Lei 13.465/2017, que dispõe sobre regularização fundiária e institucionaliza novas figuras urbanísticas, os "condomínios de lotes" e os "loteamentos de acesso controlado".

Freitas (2008) reconhece nos primeiros subúrbios ingleses e no modelo de subúrbio americano a referência conceitual para loteamentos e condomínios fechados implantados na América Latina. Na Inglaterra, o subúrbio surge nas primeiras décadas do século XIX, no contexto da revolução industrial como uma alternativa à poluição das cidades gerada pelas fábricas e como uma forma de distanciamento da classe operária. A suburbanização americana, embora baseada inicialmente no modelo inglês, adquire contornos próprios durante o século $\mathrm{XX}$, com a adoção do modelo disperso de urbanização, caracterizado pela proliferação e subúrbios conectados à área central por autoestradas, sistema dependente do uso do automóvel individual. A partir dos anos 1980, o subúrbio americano passa a ser alterado com a implantação barreiras físicas e guaritas formando espaços fechados, as gated communities, que promovem o fechamento de áreas públicas (vias, praças, parques).

Caldeira (2011, p263) afirma que no Brasil os condomínios fechados para a elite só tornaram-se significativos no final da década de 1970 , a partir do caso da região metropolitana de São Paulo a autora afirma a construção de algo semelhante às new towns e edge cities americanas, com áreas suburbanas combinando empreendimentos residenciais a centros comerciais e espaços para escritórios, a exemplo dos empreendimentos Alphaville, Aldeia da 
Serra e Tamboré, em Santana de Parnaíba e Barueri. Diversos estudos demonstram o surgimento dos primeiros condomínios fechados nas cidades médias na década de 1970, a exemplo das cidades de Marília, Presidente Prudente e São Carlos, no estado de São Paulo (SPOSITO; GÓES, 2013).

No Rio Grande do Sul, nas cidades de Caxias do Sul, Passo Fundo, Pelotas e Santa Maria foram localizados 57 condomínios fechados que remetem aos públicos de média e alta renda, de acordo com tamanho dos lotes e tipologias das edificações, no entanto com perfil heterogêneo em escala, variando de menos de uma dezena a centenas de unidades. Não tivemos acesso às leis de aprovação de todos esses empreendimentos, portanto os critérios de localização basearam-se, para os empreendimentos mais recentes, da última década especialmente, nas informações veiculadas pelos empreendedores, em ocasião dos lançamentos; os condomínios mais antigos foram localizados a partir de uma diversidade de fontes, que envolvem mapeamentos das prefeituras, menção em periódicos locais e sobretudo vistoria em foto aérea, em diferentes períodos, a partir daí foi possível reunir dados aproximados de número de lotes e períodos de implantação.

Considerando o número de empreendimentos, a cidade de Caxias de Sul se destaca com 25 condomínios, seguida de Santa Maria, com 15, Pelotas com 10, e Passo Fundo, com sete condomínios. Em Caxias do Sul, no entanto, diversos condomíni os, mapeados pela prefeitura municipal em 2008, encontram-se desocupados ou subocupados, sobre os quais não foi possível obter informações.

Nas décadas de 1980 e 1990 poucos empreendimentos são registrados nas cidades estudadas, sendo Passo Fundo a precursora, em 1984, com a implantação do condomínio Morada Além do Horizonte, localizado em área rural e destinado à residência de recreio. A década de 1990 registra os primeiros empreendimentos aos moldes dos condomínios contemporâneos, como primeira residência, dois na cidade de Caxias do Sul, três em Pelotas e dois em Santa Maria, dessa década são mais significativos os condomínio Sociedade de Medicina (1999), em Santa Maria, com 135 lotes, e o condomínio Bougainville (1995), em Pelotas, com 97 lotes.

Na década de 2000, identificamos a implantação de 23 condomínios nas cidades estudadas, sendo a maioria, 15 deles, em Caxias do Sul, três em Passo Fundo e Santa Maria e dois em Pelotas. A grande maioria dos condomínios desse período são de pequeno porte, com no máximo 50 lotes, a exceção ocorre em Passo Fundo, com o condomínio Vivenda das Palmeiras, com 197 lotes, inaugurado em 2009.

Na década de 2010 o mercado dos condomínios fechados se amplia nas quatro cidades, abarcando maior número de lotes e evidenciando estratégias 


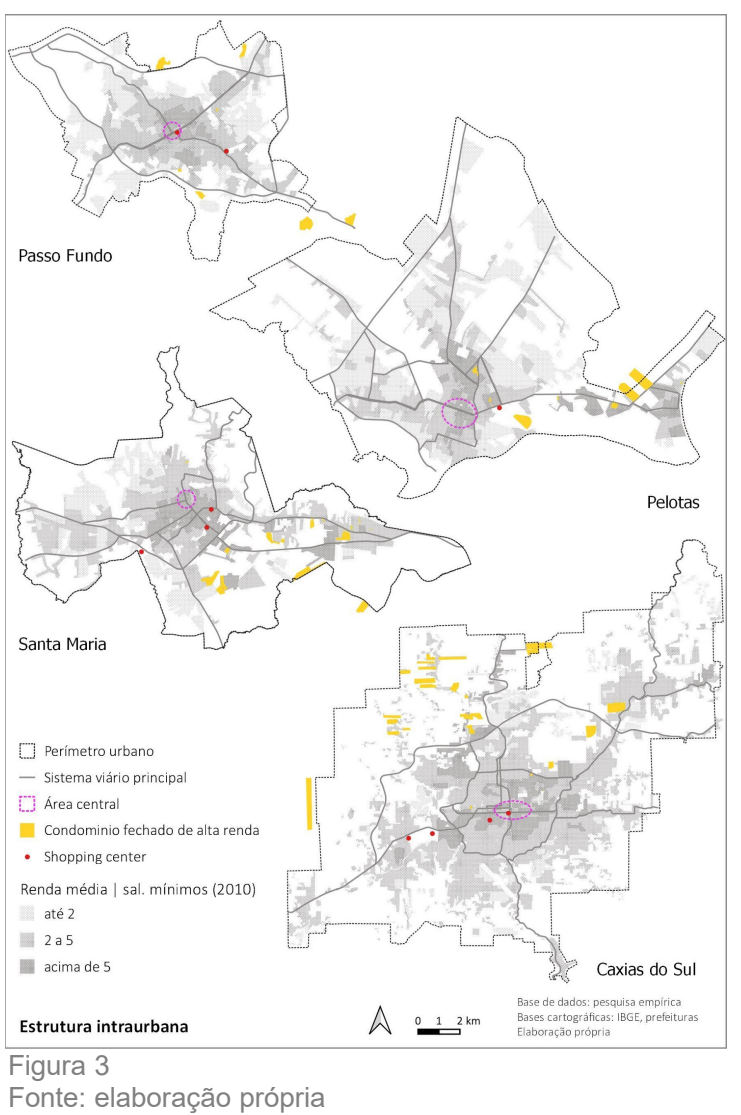

Fonte: elaboração própria comerciais planejadas. Ao todo são 23 lançamentos, nove em Santa Maria, seis em Caxias do Sul, cinco em Pelotas e três em Passo Fundo. Os condomínios variam de 23 a 454 lotes, sendo a média do período 165 lotes.

A grande maioria dos condomínios implantados na última década tem em comum a presença de áreas de uso coletivo como áreas verdes, quadras de esportes, clubes e salões de festas, o setor registra também a entrada de grandes empresas com sedes em outros estados, como a Alphaville Urbanismo, responsável pelo Alphaville Pelotas, e a Real Park, com o Real Park Santa Maria.

As estratégias de marketing se caracterizam, via de regra, pela exaltação de quatro características principais: a segurança proporcionada pelos muros, em ambientes monitorados; o uso exclusivo desses espaços; o contato com a natureza, alguns deles inclusive dotados de amenidades naturais; e por fim, a acessibilidade ao centro da cidade e equipamentos de interesse como os shopping centers, hipermercados e universidades, garantida pelo sistema viário.

\section{Reestruturação intraurbana}

Conforme demonstrado anteriormente, os shopping centers e condomínios horizontais se disseminam nas cidades de Caxias do Sul, Passo Fundo, Pelotas e Santa Maria, a partir da década de 1990.
Interessa-nos agora abordar como esses elementos influenciam nos processos de reestruturação intraurbana dessas cidades, destacando algumas especificidades, sendo o conceito de reestruturação utilizado para caracterizar rupturas significativas nas lógicas de estruturação intraurbanas precedentes.

As quatro cidades apresentam processos de estruturação similares durante todo o século XX, caracterizados pelo crescimento urbano em torno do centro principal, e a estrutura social definida pelo modelo centro-periferia, com uma gradação dos estratos sociais, sendo as periferias ocupadas pelos mais pobres.

Esse modelo socioespacial, no entanto, passa a ser modificado no final do século XX, em ritmos particulares, sendo os shoppings e condomínios elementos importantes nesse processo. Os shoppings centers, incialmente construídos nas áreas centrais, se dispersam pelas periferias, os condomínios, por sua vez, surgem periféricos, implantados em áreas até então desvalorizadas, vizinhas de bairros populares, e às vezes em áreas rurais.

Os mapas apresentados na figura 3 sobrepõem as localizações dos shoppings e condomínios aos extratos de renda da população, representados, simplificadamente, por três classes de renda (baixa, média e alta), os shoppings e condomínios foram mapeados com base em levantamento empírico e dados disponibilizados pelas prefeituras municipais. 
Os extratos de renda foram definidos a partir da variável Renda Média do Responsável, extraída dos Dados do Universo do Censo Demográfico do IBGE, de 2010, esta variável não contempla, portanto, uma parcela significativa dos condomínios fechados, construídos posteriormente.

Relativo aos shopping centers, na década de 1990, observa-se que as localização centrais, junto ao comércio de rua, de certa forma se sobrepõem às tradicionais galerias comerciais, populares nas décadas de 1970 e 1980, sendo possível pressupor certa elitização dos comércios e serviços no interior desses espaços, ainda que os mesmos reforcem a importância funcional e simbólica das áreas centrais, associada também à proximidade das camadas de alta renda. Nos casos de Caxias do Sul e Passo Fundo, os primeiros shoppings, Prataviera e Bella Città, respectivamente, se localizam em área central, em Santa Maria, os shoppings Monet e Royal Plaza são construídos em bairros predominantemente residenciais, vizinhos ao centro, respectivamente, N. Sra. de Lourdes e N. Sra. das Dores.

A dispersão dos shoppings pelas periferias tem três significados importantes: primeiro, a formação de novos centros junto a esses equipamentos; segundo, o reforço da capacidade de atração das cidades estudas sobre a região, daí as implantações próxima as saídas, junto às rodovias; por fim, o reforço de novos vetores de concentração das clas- ses de alta renda em determinados setores urbanos, como no caso de Pelotas, no setor leste. Esse processo ocorre primeiramente em Caxias do Sul, ainda na década de 1990, com a construção dos shoppings Iguatemi, no bairro Sanvito, e Martcenter, no bairro Desvio Rizzo, os dois na periferia sudoeste, na saída da cidade, junto à rodovia RS122, mais recentemente, em 2010, é implantado o shopping Bourbon San Pelegrino, no bairro San Pelegrino, nesse caso um bairro mais próximo da área central, de classe média alta. Em Santa Maria, o shopping Praça Nova está localizado no bairro Urlândia, às margens da BR 158, periferia sul da cidade, envolto por bairros populares. Em Passo Fundo, o Passo Fundo Shopping (2018) localiza-se na avenida Presidente Vargas, o principal eixo viário da porção sudeste da cidade, no bairro São Cristóvão, de classe média. Por fim, o shopping Pelotas (2013) está localizado no bairro Areal, na Avenida Ferreira Viana, mais importante eixo viário de conexão do centro à porção leste da cidade, sentido Laranjal, em área de concentração de camadas de alta renda.

Relativo às estratégias locacionais dos condomínios fechados, têm-se como característica comum às quatro cidades as localizações periféricas, predominantemente de média e baixa renda, nas franjas urbanas, ou em áreas rurais, como no caso dos condomínios Vila Palladio e Morada Além do Horizonte, em Passo Fundo. A existência de eixos viários estruturadores, especialmente com acesso à área 
central, revela-se essencial a essas localizações

Nas cidades de Caxias do Sul, Pelotas e Santa Maria, percebe-se a concentração de condomínios em determinados setores urbanos: norte, em Caxias, nos bairros N. Sra. da Saúde, Pedancino e Serrano, áreas pouco ocupadas e com presença significativa de mata nativa; em Pelotas, na porção leste da cidade, nas proximidades da área do balneário Laranjal; e em Santa Maria, na zona leste, nas imediações do bairro Camobi. Em Passo Fundo, os condomínios se distribuem na metade oeste da cidade, ao norte junto aos bairros São José e Vila Fátima, nas proximidades da Universidade de Passo Fundo, a sul, junto ao bairro Lucas Araújo e na saída da cidade, sentido sudeste, em área rural.

Analisando-se as relações entre as localizações dos shoppings e dos condomínios, percebe-se nas cidades de Santa Maria e sobretudo Pelotas, coincide a direção de implantação desses equipamentos, em Santa Maria partindo do centro, passando pelos shoppings Monet e Plaza, sentido bairro Camobi (leste), em Pelotas partindo do centro na direção leste, sentido Laranjal, ao longo da Avenida Ferreira Viana. Em Passo Fundo, o Passo Fundo Shopping, na Avenida Presidente Vargas, se aproxima dos condomínios da porção sudeste da cidade, no entanto, se distancia dos condomínios ao norte. Em Caxias do Sul, pelo contrário, as localizações dos shopping centers, nos bairros Desvio Rizzo e Sanvitto, se opõe aos condomínios, con centrados na zona norte da cidade.

Alguns elementos contribuem para explicar essas diferenciações. Nos casos de Pelotas e Santa Maria, há vetores de atração importantes nos setores leste das duas cidades, o balneário Laranjal, em Pelotas, e o campus da UFSM, em Santa Maria. Nos dois casos, pode-se mencionar a conformação de setores de amenidades ao longo das últimas décadas, em Santa Maria, desde a década de 1960, quando foi implantada a universidade, motivando o desenvolvimento e valorização imobiliária do bairro Camobi, e em Pelotas, desde a década de 1950, quando o balneário Laranjal, junto à Lagoa dos $\mathrm{Pa}$ tos, se integra à cidade, configurando-se como um vetor de expansão das classes de média e alta renda. A conformação de setores de amenidades é entendida no caso de Santa Maria a partir de um grande investimento público, e no caso de Pelotas em função de características naturais, às quais se sobrepõe o processo de urbanização, a partir de investimentos em infraestrutura, sobretudo viária.

No caso de Passo Fundo, na ausência de um vetor significativo de desenvolvimento urbano, parece não haver ainda uma a eleição clara de um setor predominante de expansão das classes de alta renda, se por um lado a presença do novo shopping no bairro São Cristóvão reforça o vetor leste, a implantação do bairro Cidade Nova na zona norte, nas proximidades do bairro Vila Fátima e da Universidade de Passo Fundo, evidencia o vetor norte. No caso de 
Caxias do Sul, pode-se aferir que a grande concentração de condomínios na zona norte da cidade associa-se às amenidades naturais da região, em área com características rurais, com paisagem exuberante. A localização dos shoppings, em Caxias do Sul, no entanto, reforça áreas tradicionalmente de alta renda, junto ao bairro San Pellegrino, e por outro lado indica a abrangência regional desses equipamentos, nos casos dos shoppings Martcenter e Iguatemi, na saída para a cidade de Farroupilha, na RS 122.

Nos quatro casos, mesmo diante de especificidades, evidenciam-se processos de reestruturação intraurbana em curso, caracterizados por novos padrões de autossegregação dos mais ricos nos condomínios fechados periféricos e pela emergência de novas expressões das centralidades, através dos shopping centers. Esses dois equipamentos, associados ao sistema viário, viabilizam novas formas de morar e de consumir, revelando alterações nas dinâmicas cotidianas e nas práticas de sociabilização da população. A disseminação dos shopping centers e condomínios simultaneamente fortalecem e configuram setores de amenidades nessas cidades, processo mais avançado em $\mathrm{Pe}-$ lotas e Santa Maria, mas também em curso em Caxias do Sul e Passo Fundo.

Essas transformações indicam maior fragmentação dos territórios, representando a superação dos tradicionais processos de segregação residencial.
Segundo Sposito e Goés (2013) os processos de fragmentação socioespacial são posteriores à segregação, envolvendo além do uso residencial, a existência de policentralidades, a conformação de territórios descontínuos, a ocorrência de contiguidade sem continuidade (a exemplo dos condomínios fechados), e o aparecimento de áreas mistas. Esses processos, típicos das metrópoles, passam a ocorrer também em cidades médias, porém com níveis de complexidade inferiores.

\section{Conclusões}

As dinâmicas urbanas analisadas nesse texto, a partir do recorte empírico centrado em cidades médias gaúchas, evidenciam a ocorrência de processos de reestruturação intraurbana em curso, nos quais a disseminação de shopping centers e condomínios fechados de alta renda são emblemáticos. Se por um lado representam "inovações urbanísticas", nos termos de Corrêa (2013), instrumentais à reprodução do capitalismo, por outro lado expressam novas lógicas de produção do espaço urbano que conduzem ao agravamento da fragmentação socioespacial.

Nesse texto, buscamos analisar as lógicas locacionais desses dois elementos nas cidades estudadas, enfatizando suas repercussões nas respectivas estruturas intraurbanas. Duas constatações importantes emergem dessa análise: a formação de novas expressões da centralidade, associadas aos shop- 
ping centers, competindo com o centro principal, e a ressignificação da periferia a partir da implantação de condomínios fechados de alta renda, em áreas tradicionalmente ocupadas pelos mais pobres. Esses fatos juntos conduzem à constatação de transformações importantes na estrutura socioespacial, superando os padrões de segregação centro-periferia.

Essa constatação é fundamental à compreensão das dinâmicas urbanas contemporâneas em cidades médias, nesse sentido, têm enorme potencial explicativo, devendo extrapolar o tom de denúncia por vezes adotado em algumas abordagens.

Por fim, a título de reflexão, levantamos a hipótese que o sucesso de empreendimentos como shopping centers e condomínios fechados em cidades médias tem por base três fundamentos: primeiro, essas cidades representam mercados consumidores em potencial; segundo, o discurso da insegurança fundamenta a disseminação de espaços fechados como alternativa à vida na cidade, que de fato encontra bases na realidade, à medida que a violência urbana se amplia também nas cidades médias; por fim, de certa forma as cidades médias reproduzem o modelo de desenvolvimento urbano metropolitano, ansiando por inovações. Têm-se nesse último ponto, a reprodução de um discurso ultrapassado, do progresso associado à novidade e à obsolescência das formas, mesclando-se inte- resses capitalistas, práticas de planejamento e gestão urbanas equivocadas, além dos valores e ideais de uma sociedade marcada pelas desigualdades.

\section{Referências}

ABRASCE. Associação Brasileira de Shopping Centers. Disponível em: < https://abrasce.com.br/>. Acesso em: 14. Abr. 2020.

CALDEIRA, Teresa Pires. Cidade de muros: crime, segregação e cidadania em São Paulo. São Paulo: Editora 34, 2000.

CORRÊA, Roberto Lobato. Segregação residencial: classes sociais e espaço urbano. In: VASCONCELOS, P. A.; CORRÊA, R. L.; PINTAUDI, S. M. (orgs.). A cidade contemporânea: segregação socioespacial. São Paulo: Editora Contexto, 2013, pp. 39-60.

FREITAS, Eleusina Lavôr Holanda de. Loteamentos fechados. Tese (Doutorado em Habitat) - Faculdade de Arquitetura e Urbanismo, Universidade de São Paulo, São Paulo, 2008.

FRÚGOLI JR., Heitor. Os shoppings de São Paulo e a trama do urbano: um olhar antropológico. In : PINTAUDI, Silvana Maria; FRÚGOLI Jr., Heitor (orgs). Shopping centers : espaço, cultura e 
modernidadde nas cidades brasileiras. São Paulo : Editora Unesp, 1992, p. 75-92.

LOYOLLA, Leonardo Coelho. Reflexões sobre os Possíveis Impactos da Lei Federal 13.465/2017 nos Sistemas de Espaços Livres das Cidades Brasileiras. In : XIII Colóquio QUAPA SEL, 01 e 02, out. 2018, Santa Maria. Disponível em :< http://quapa.fau.usp.br/wordpress/wp-content/uploads/2018/12/ANAIS-XIII-COLO\%CC\%81QUIOQUAPASEL-parte-1.pdf>. Acesso em: 20 mar. 2020.

PINTAUDI, Silvana Maria. Os shopping centers no Brasil : condições de surgimento e estratégias de localização. In : PINTAUDI, Silvana Maria ; FRÚGOLI Jr., Heitor (orgs). Shopping centers : espaço, cultura e modernidadde nas cidades brasileiras. São Paulo : Editora Unesp, 1992, p. 15-44.

SPOSITO, Eliseu Savério; SPOSITO, Maria Encarnação Beltrão; SOBARZO, Oscar. (orgs.). Cidades Médias: produção do espaço urbano e regional. São Paulo: Expressão Popular, 2006.

SPOSITO, Maria Encarnação Beltrão (org.). Cidades Médias: espaços em transição. São Paulo: Expressão Popular, 2007.

SPOSITO, Maria Encarnação Beltrão; GOÉS, Eda Maria. Espaços fechados e cidades: inseguran- ça urbana e fragmentação socioespacial. Presidente Prudente: Editora Unesp, 2013.

SPOSITO, Maria Encarnação Beltrão; ELIAS, Denise; SOARES, Beatriz Ribeiro (orgs.). Agentes econômicos e reestruturação urbana e regional: Passo Fundo e Mossoró. São Paulo: Expressão Popular, 2010.

Agentes econômicos e reestruturação urbana e regional: Tandil e Uberlândia. São Paulo: Expressão Popular, 2010.

Agentes

econômicos e reestruturação urbana e regional: Chillán e Marília. São Paulo: Expressão Popular, 2012.

Agentes econômicos e reestruturação urbana e regional: Campina Grande e Londrina. São Paulo: Expressão Popular, 2013.

Agentes

econômicos e reestruturação urbana e regional: 
Marabá e Los Ángeles. São Paulo: Cultura Acadêmica, 2015.

\section{Agentes}

econômicos e reestruturação urbana e regional: Dourados e Chapecó. São Paulo: Cultura Acadêmica, 2016. 